\title{
The teaching of medical ethics to medical students
}

\author{
Shimon M Glick Ben-Gurion University of the Negev, Beer-Sheva, Israel
}

\begin{abstract}
Teaching medical ethics to medical students in a pluralistic society is a challenging task. Teachers of ethics have obligations not just to teach the subject matter but to help create an academic environment in which well motivated students have reinforcement of their inherent good qualities. Emphasis should be placed on the ethical aspects of daily medical practice and not just on the dramatic dilemmas raised by modern technology. Interdisciplinary teaching should be encouraged and teaching should span the entire duration of medical studies. Attention should be paid particularly to ethical problems faced by the students themselves, preferably at the time when the problems are most on the students' minds. A high level of academic demands, including critical examination of students' progress is recommended. Finally, personal humility on the part of teachers can help set a good example for students to follow.
\end{abstract}

When I attended medical school in the early 1950s in the United States I had no formal courses in medical ethics. The syllabus of my institution did not even mention the word ethics, nor was there even the remotest hint about the subject or any related area. To the best of my knowledge, the only American medical schools in those days that discussed the subject of medical ethics were those under Roman Catholic auspices such as Loyola and Georgetown. Those courses were essentially an outline of the Roman Catholic view on a variety of bioethical issues. A significant portion of the student body did not follow those decisions in their subsequent practice. This discrepancy between theory and practice still represents one of the key problems besetting the teaching of bioethics everywhere.

There are still some individuals, mostly physicians, extant whom those in the ethics field regard as fossils, who question the entire enterprise of teaching medical ethics to medical students.

One such physician, Thurston Brewin, wrote an article in the Lancet (1) entitled 'How much ethics is

\section{Key words}

Teaching medical ethics. needed to make a good doctor?' The first paragraph of his article reads:

'The most caring doctor may be totally ignorant of academic ethics. And this should come as no surprise. Has anyone ever said about a friend or neighbour that the reason he is thoughtful and kind is that he has studied ethics?'

Of course we know better than these sceptics, we reassure one another, and indeed it is not difficult to refute Brewin's position. But, in reality, even the most unpopular questions deserve answers, particularly since they do articulate a view stilite prevalent among all too many physicians and because these questions often contain a grain of truth Philosophers teaching bioethics often ask similar questions, albeit in more sophisticated language.

I would like to preface my comments by describing briefly my background and prejudices. I was raised in an orthodox Jewish home where I learnt absolutely nothing about my human rights, but a great deal about my duties to others. It seemed to me that if rights existed, they were reserved for others.

Some of the religious teachers in my high school days frequently discussed and placed major emphasis on ethical behaviour in interpersonal relationships, and they were remarkably saintly role models themselves. (The personal conduct of ethicists is another issue that deserves more attention than it has received in our circles.) When I left for university to study medicine, the parting words of the rabbi were: 'Remember, never become callous to human suffering'. This parting admonition has remained with me throughout my professional life, and remains a necessary, albeit insufficient, prerequisite for ethical behaviour on the part of the physician.

Today, I come to medical ethics as a practising orthodox Jew who believes that for many of the bioethical issues that are under discussion, there are right and wrong answers. Yet, I teach in a pluralistic university and society which do not necessarily accept my views on a variety of issues and I often teach about positions which I personally oppose. 
I am a physician and not a philosopher (not even an amateur philosopher), and I spend most of my professional life caring for patients and teaching medicine. Ethics is a sort of hobby for me. This situation has serious disadvantages because of my lack of professionalism in ethics, but offers a tremendous advantage because medical students in general learn most willingly from physicians. This is a world-wide phenomenon - unfortunate, but true. Furthermore, I can perhaps relate more empathically with the real-tolife problems faced by medical personnel.

Just about a decade ago, in July, 1983, a conference was held at Dartmouth College, where ten participants, world leaders in medical ethics education, proposed basic curricular goals in medical ethics, which were subsequently published (2). This document is a useful starting point, and I will refer to it from time to time. I found it helpful, though at times a bit too narrow, culturally specific and overly professional. The authors preface their recommendations with a belief, which I share, that the basic moral character of medical students has been formed by the time they enter medical school. They therefore contend that the curriculum should not attempt 'to try to improve the moral character of future physicians, but to provide those of sound moral character with the intellectual tools and interactional skills to give that moral character its best behavioural expression' (2).

This point is well taken and convincingly articulated, yet I feel that the attitude is a bit too intellectual and detached - as might be expected from a group of philosopher-scholars.

There is not enough of the passion that might be expected about moral issues. I prefer a somewhat broader involvement on the part of teachers interested in promoting ethical behaviour by future physicians.

Firstly, staff members of a medical school have a moral obligation to act within their own institutions to promote an admission process which indeed will give preference to candidates of higher moral character. Admittedly this is not an easy task, but I believe we could do better than we are if a conscious effort were to be made. At our own institution, we have shown that an extensive investment in our interview process selects a cohort with a higher score on a test of ethical reasoning, as expressed in the Rest Ethical Issues Identification Test, than those at another Israeli medical school without such an interview step (3). I cite this result in spite of my scepticism whether a higher Kohlberg stage necessarily correlates with better ethical behaviour, as Rest and others contend.

\section{Ethical sensitivity}

Given a highly intelligent, well motivated student body of reasonable moral character, I believe that we must do more than just provide 'the intellectual tools and interactional skills to deal with ethical problems'.
I think we should act to heighten the students' ethical sensitivity, to enhance their ethical performance and, at the very least, to prevent the erosion that almost invariably occurs in those qualities during the medical school years, if insufficient attention is paid to this area of endeavour.

For example, one of our first encounters with the students, even before they start the academic year, is the showing of a popular movie on a medically related topic, with the discussion centring on the students' attempts to identify every possible ethical issue they notice. When the session is over, and perhaps 20 ethical issues have been detected, the message is conveyed that ethical issues abound in almost every patient-physician encounter.

The Dartmouth document appropriately places the ability to identify the moral aspect of medical practice as the first curricular agenda item. This point is critical and unfortunately not sufficiently appreciated. When bioethics is discussed in the media and by physicians, what are usually conjured up are 'Brave New World' dilemmas such as genetic engineering, surrogate motherhood and transplantation, when in reality the prosaic day-to-day interactions with patients are far more pervasive and important. And the moral failings of the individual physician and the profession which underlie the public's discontent, are more likely to result from the routine doctor-patient contacts than from the dramatic headline-making issues.

In keeping with the goal of suffusing the entire area of physician-patient contact with ethical content, ideally medical ethics would be taught in a world where every medical teacher were personally committed to such a philosophy and practised it at the bedside. Thus the student would be exposed throughout his or her education to role models who practised and taught ethics in the context of their discussions on surgery, paediatrics or obstetrics. Such role models would not confine their discussion of a patient to the pathophysiology, metabolism and biochemistry of the disease process, and would also go beyond the psychosocial aspects of the case. They would deal also with the ethical aspects on a regular basis when appropriate. This ideal situation exists nowhere to my knowledge, nor is it likely ever to exist before the advent of the Messiah. I mention it not just to hold out before you a Utopian ideal about which one can just fantasize. But if we keep this ideal in mind, it will help us to strive to heighten the ethical knowledge and skills of the clinicians and gradually to build up a nucleus of physicians who, if not professional ethicists, have enough background, interest and ability in the field to be able to discuss intelligently with the student, the ethical aspects of their clinical cases.

In this regard, I should like to mention the recently reported approach of the medical school in Newcastle, Australia which has a multi-year programme of medical ethics teaching which involves 
some 41 teachers (4). Twenty-seven are clinicians, and only two are trained bioethicists, the rest being lawyers, philosophers, theologians, and sociologists. In every university community there may be dozens of highly talented people in related fields who would be delighted and honoured to be invited to participate in student tutorials several times a year. Clinicians with an interest in bioethics can be trained, particularly in specific areas of special interest.

When tutorials are given by a team which may consist of a bioethicist, a clinician and a lawyer, the interactions are instructive in themselves, and the novice teachers of bioethics become increasingly sophisticated and involved. In this way, over several years, a large and effective teaching staff can be assembled for relatively low cost. There are other fringe benefits of enlisting individuals from different disciplines. For instance, they can provide refreshing insights, often missed by super-specialists.

There is another area of involvement which is not generally included under bioethics, and certainly it does not fall into the philosophical disciplines. It is not normally listed under curricula of medical ethics, and I am sure some of the bioethics professionals will take serious issue with its inclusion under bioethics teaching. I am referring to the area of empathy or compassion in the physician-patient relationship, the ability to identify with the patient, with his or her needs and feelings. For example, much emphasis is given and, appropriately, to the ability to obtain a valid consent for treatment.

The ability to carry out this task is contingent not only on understanding the legal fine points of consent or of competence. To differentiate between what constitutes insufficient, adequate, or excessive information for a patient requires a unique kind of relationship, one of empathy, insight and sensitivity. A physician lacking such qualities may not appreciate the subtleties involved, nor even the need for a truly informed decision. Nor can an explanation be appropriately geared to the patient's needs without the requisite identification with the patient. In our school, we place great emphasis and spend much time on early clinical exposure. Much of this focus is on communication skills and on learning the meaning of illness to a patient and his or her family.

A new programme of which we are particularly proud, is the week that first-year students spend with the disabled. Students devote a week to familiarizing themselves intimately with the world of the blind, deaf and mentally retarded. This experience is emotionally enriching and informative, and seems to enhance compassion.

None of this is pure ethics, but to practise medicine without appropriate compassion or sensitivity is unethical. While it is not to be argued that professional bioethicists should be teaching these skills, they do have a responsibility as faculty members to encourage the inclusion of this category of subjects and experiences in the curricula of their schools.

There is another area of ethical problems which is only now beginning to gain some attention, and that is the range of problems faced by students themselves in the course of their studies. The Association of American Medical Colleges (AAMC) has begun to look at this area (5) because of the attention which has recently been focused on unethical behaviour by researchers, and the data that suggest that such behaviour may have its roots much earlier, during student days. Students face problems of coping with unethical behaviour by their superiors, and of being pressured to carry out activities for which they are untrained or which they may believe to be unethical, as well as having to deal with a variety of other problems which for them may be burning issues. There should be room in the curriculum for an airing and a focus on these problems.

How does one teach ethics in a pluralistic setting in which there is no real consensus among either students or faculty? Here, the conscientious teacher of whatever view, needs to straddle a tightrope between attempts at indoctrination or persuasion to his particular point of view, and a kind of ethical relativism where every point of view is considered legitimate as long as it is well-intentioned and logically argued.

The skilful and ethical instructor (and there are rules of ethics for teachers as well as physicians), should act as the devil's advocate towards every point of view expressed, forcing students to clarify their thought processes, defend their positions logically and be able to articulate them. There will generally be few minds changed at any given session, but in the best of situations, a clarity of thought and an understanding of the principles involved, including those opposing one's own, will take place. The instructor need not hide his/her own particular viewpoint, but he/she must be careful not to abuse the power and authority inherent in his/her position.

\section{When and how to teach ethics}

If we follow the classical breakdown between the pre-clinical and clinical years - or as some wags put it, the pre-cynical and the cynical years, it would seem logical that initially one should teach a formal, rigorous course in philosophy and theoretical ethics, and only subsequently embark on case-centred clinical ethics. But logical as that sounds, I would suggest that such a course of action would represent a serious error and may even be disastrous. Firstly, even in the hard scientific subjects, there is an increasing tendency in progressive medical schools to start early with clinical problems, and learn the physiology, biochemistry and molecular biology in connection with a solution for the clinical problems. This is the basis of the problem-based curriculum. 
This approach has been carried to an extreme in a few schools where the entire curriculum is problembased, but even the more traditional institutions are finding increasingly that medical students learn better when the basic sciences are integrated with clinical case material. The situation is even more critical for the humanities and social sciences.

Medical students are notorious for their intolerance of some of these subjects, particularly when taught as separate courses detached from clinical problems. The students learn best when they can bring the particular social science discipline to bear on the solution of a specific medical problem. These student attitudes are common not only in traditional medical schools; even in the communityoriented institutions with a positive attitude towards social sciences, medical students tend to be pragmatists and to have little patience for theoretical social sciences and even less for philosophy. Therefore, most successful teaching programmes in bioethics for medical personnel appropriately emphasize the use of cases as much as possible, with the theoretical principles derived during a discussion of cases. The use of currently active live cases from the students' own experience offers the advantage of excitement, relevance and immediacy, but does not lend itself to providing an organized pre-planned and orderly teaching programme. I think one can use pre-chosen cases from the literature or from one's own experience. A very useful textbook is that of Pence (6), which is based on classic cases in bioethical history or Bette-Jane Crigger's collection of cases from the Hastings Center Report (7).

I am prejudiced against a single, defined course in bioethics during medical school as the only exposure in teaching, no matter at what stage it is given. Such a formal, one-time course encourages the attitude: 'I have finished ethics, now let us continue with the real world'. The message that we must convey is that bioethical dilemmas are a ubiquitous part of the physician's professional life and should be an integral part of all medical training. Therefore, I favour a substantial amount of - 'injection' teaching of bioethical subjects, each in the particular medical context. When dealing with obstetrics and gynaecology is the time to discuss ethical problems in reproduction. A course in epidemiology is a good opportunity to discuss the ethics of clinical trials. And when AIDS is discussed in infectious diseases, the focus may be on confidentiality and on the responsibility of the physician to risk his/her life in the line of duty.

Students relate best to subject matter about which they are actively thinking and are already troubled. This kind of spot-teaching does not preclude, in addition, a formal course in ethics. We do our formal course as part of our 'Physician and society' course, which is given as a grand finale, almost at the end of the student's 6 th year. During this period, we devote time to medical ethics, legal medicine, medical economics, health policy issues and the like, as a summing up of the physician's role in society, at the $\overrightarrow{\overline{\bar{V}}}$. threshold of the student entering into independent $\delta$ professional life.

One person's principled belief is for another $\stackrel{\vec{F}}{\rightarrow}$ individual, a rigid dogma. I have had the opportunity $\bar{c}$ to be trained in the United States of America and $\overline{\bar{N}}$ then move to Israel. In fact, this summer, after $19 \frac{\bar{\rho}}{\square}$ years in Israel, I am at the break-even point, where I $\stackrel{\Phi}{\varrho}$ have spent exactly the same number of years in medicine in each country. I came to Israel full of the $\vec{\circ}$ conviction that the way we did it 'back home' was great and my function was to convince the 'natives' $\vec{\omega}$ of the superiority of my American viewpoint. I did $\stackrel{5}{S}$ manage to teach a good deal and to produce some $\overline{\overline{0}}$ change, but I also learnt a great deal from the in 'natives'. Israel is an incredibly heterogeneous cultural setting and this is enriching. In the academic in field of medical ethics, it is quite clear that at the $\underset{\mathcal{C}}{\mathscr{C}}$ moment, the field is an almost purely western 음 domain, to the exclusion of most other viewpoints. There is a certain monolithic quality about the field. For example, the great emphasis on autonomy and $\underset{\varnothing}{\mathscr{\infty}}$ on truth-telling is remarkable for its unanimity in an 3 almost dogmatic manner and one rarely finds these views questioned. At a conference a few years ago on transcultural dimensions of medical ethics, Profess 8 C M Francis of India related that in his country physician had been convicted for failing to impo indicated therapy on an unwilling patient. An this year, when we discussed the conclusions of the Appleton Conference (8) on decisions about withdrawal of therapy with senior Israeli medical $\stackrel{\complement}{\varrho}$ students, I found that about half of them stated that $\overrightarrow{\vec{O}}$ they would not allow a patient to die even if this were $\frac{3}{3}$ his or her wish if there was an unequivocal indication for therapy.

A large number of the students went so far as to indicate they would be willing to risk a law suit for $\bar{\emptyset}$ assault rather than let a patient die. Several reported specific incidents from their clerkship where such therapy indeed was imposed against patients' wisheso and the patients subsequently thanked them for $₹$ doing so.

\section{Dogmatism}

These views are anathema to most western bioethicists and I have the distinct impression that the dogmatism of our liberal western bioethics $\omega$ establishment is no less than that of Roman Catholic priests or orthodox Jewish rabbis in the past. It iso well that we recognize our own limitations andळ convey our views with a bit more humility. John ${ }^{\text {? }}$ Stuart Mill, one of the spiritual fathers of the concept of autonomy, was not willing to extend autonomy to permit the wilful selling of oneself into? slavery, because he would not countenance the use $\mathbb{Q}$ of freedom to destroy freedom (9). Suicide is obviously a more serious and permanent breach of 
autonomy than a sale into slavery, for by suicide we lose our freedom forever, whereas with slavery there is always a possibility of escape or liberation.

In the area of truth-telling too, the American and Scandinavian axis is almost absolutist in its approach in teaching one 'right' way. This is a product of American individualism and the doctrine that each patient has an inalienable right to know about his or her illness. I too felt similarly. More recently, I have come into contact with a multitude of immigrants from Eastern Europe and Ethiopia. In both of these cultures, both patient and physician demand concealment of bad news, and I have learnt to respect this wish at times in direct contradiction to all that I was taught and was teaching. I am pleased to note that over the last year or two, there have appeared in the western literature, a questioning of absolute truth-telling $(10,11)$.

I raise both points because I suspect that we are members of a self-appointed, replicating inbred group and there is a danger of self-serving smugness in our consensus attitudes which we then convey to students.

I suggest that we expand our horizons a bit beyond our own cultures and at least listen to other voices and try to cultivate in our students a healthy scepticism even towards our own points of view. Finally, how do we evaluate these courses?

Here, I would like to endorse with enthusiasm, but with regret, the Dartmouth recommendations that students' learning be measured by means of 'reasonably difficult examinations or required papers or both'. Our medical school is characterized by a relatively open and free relationship between faculty and student. In the early years of the school, the course 'Physician and society' did not conclude with an examination. But there was a distinct disproportion between the popularity of the course which was very high, and the degree of student effort and attendance. After one or two years' experience with the course, I became convinced that students need the additional stimulation of an examination in order for them to take the course seriously enough. And so, I have an annual debate with the students at the outset of the course at which time I am told that it is regrettable that I spoil such a wonderful course by exams. But I have been around long enough not to be made to feel guilty and not to be convinced by that argument. The students still enjoy the course and they complain a bit, but they participate more actively and their attendance is now excellent. Those few students who do not take the course seriously often fail the exam and have to sweat a bit over additional required papers before they get a passing grade and can begin their internship.

In closing, I would like to cite a quotation from Goethe's Faust which sums up the subject perfectly:

'I've now alas! Philosophy

medicine and jurisprudence too

and to my cost theology

with ardent labour studied through

and here I stand, with all my lore

Poor fool no wiser than before ...' (12).

Shimon M Glick, MD, is Chairman of the Center for Medical Education, Faculty of Health Sciences, BenGurion University of the Negev, Israel.

\section{References}

(1) Berwin T. How much ethics is needed to make a good doctor? Lancet 1993; 341: 161-163.

(2) Culver C M, Clouser K D, Gert B, et al. Basic curricular goals in medical ethics. New England journal of medicine 1985; 312: 253-256.

(3) Benor D E, Notzer N, Sheehan T J, Norman G R. Moral reasoning as a criterion for admission to medical school. Medical education 1984; 18: 423-428.

(4) Mitchell K R, Lovatt T J, Myser C M. Teaching bioethics to medical students: the Newcastle experience. Medical education 1992; 26: 290-300.

(5) Bickel J. Promoting medical students' ethical development: a resource guide. Washington, DC: Association of American Medical Colleges, 1993.

(6) Pence G E. Classic cases in medical ethics. New York: McGraw-Hill, 1990.

(7) Crigger B J. Cases in bioethics: selection from the Hastings Center. New York: St Martin, 1993.

(8) Stanley J M, et al. The Appleton International Conference. Developing guidelines for decisions to forgo life - prolonging medical treatment. Fournal of medical ethics 1992; 18 (suppl): 1-22.

(9) Mill J S. On liberty. In: Robson J M, ed. Collected works. Toronto: Toronto University Press, 1977. First published, 1859.

(10) Pellegrino E D. Is truth telling to the patient a cultural artifact? fournal of the American Medical Association 1992; 268: 1734-1735.

(11) Freedman B. Offering truth: one ethical approach to the uninformed cancer patient. Archives of internal medicine 1993; 153: 572-576.

(12) Goethe J W. Faust. 